\title{
Enhanced Outdoor Thermal Comfort Through Natural Design Technique: In-Situ Measurement and Microclimate Simulation
}

\author{
Bouthaina Sayad $^{1}$, Djamel Alkama ${ }^{2}$, Redha Rebhi $^{3,4}$, Ali Kidar $^{5,6}$, Giulio Lorenzini $^{7 *}$, Hijaz Ahmad ${ }^{8}$, Younes Menni $^{9}$ \\ ${ }^{1}$ Department Civil Engineering and Hydraulics Laboratory, University 8 Mai 1945-Guelma, Guelma 24000, Algeria \\ ${ }^{2}$ Department of Architecture, Universite 8 Mai 1945-Guelma, Guelma 24000, Algeria \\ ${ }^{3}$ Department of Mechanical Engineering, Faculty of Technology, University of Medea, Medea 26000, Algeria \\ ${ }^{4}$ LERM - Renewable Energy and Materials Laboratory, University of Medea, Medea 26000, Algeria \\ ${ }^{5}$ Faculty of Exact Sciences and Informatics, Ziane Achour University of Djelfa, P.O. Box 3117, Djelfa, Algeria \\ ${ }^{6}$ Faculty of Sciences and Technology, Ziane Achour University of Djelfa, P.O. Box 3117, Djelfa, Algeria \\ ${ }^{7}$ Department of Engineering and Architecture, University of Parma, Parco Area delle Scienze, 181/A, Parma 43124, Italy \\ ${ }^{8}$ Department of Basic Science, University of Engineering and Technology, Peshawar 25000, Pakistan \\ ${ }^{9}$ Unit of Research on Materials and Renewable Energies, Faculty of Sciences, Department of Physics, Abou Bakr Belkaid \\ University, P.O. Box 119, Tlemcen 13000, Algeria
}

Corresponding Author Email: Giulio.lorenzini@unipr.it

https://doi.org/10.18280/i2m.200302

Received: 2 April 2021

Accepted: 28 May 2021

\section{Keywords:}

thermal outdoor comfort, Vegetation, water bodies, natural design strategy, hot summer, numerical simulation, in-situ measurement

\begin{abstract}
Natural design has become the key solution to promote attractive and comfortable outdoor spaces. This study aims to investigate the effect of natural elements; vegetation and water bodies to enhance the outdoor thermal comfort levels of Martyrs square located in Guelma city, Algeria in summertime. The scientific methodology was based in measuring microclimate parameters at multiple locations within the square during the hottest period of 2019 , to be used as input to simulate four scenarios investigating the role of natural elements on outdoor thermal comfort using Envi-Met model. Microclimatic variation and PET index were obtained over a period of 12 hours and used to quantify the thermal outdoor comfort levels in different simulations. Findings indicate that the current natural design generates three hierarchical levels of thermal comfort; morning level where PET $\leq$ $45^{\circ}$; afternoon level where $45^{\circ} \geq \mathrm{PET} \geq 41^{\circ}$ and evening level PET $\leq 38^{\circ}$. Removing natural elements in scenario 2 and 3 has significantly influenced the thermal comfort levels, the thermal local effect of the water body in daytime is considered as negligible compared to vegetation where PET was over $53^{\circ}$. The natural design strategy generates two thermal comfort levels; morning and evening period with PET $\leq 41^{\circ}$ and afternoon level with $\mathrm{PET} \geq 48^{\circ}$. The results reveal that combining linear water bodies with dense trees can reduce the PET index to $9.5^{\circ} \mathrm{C}$ in the morning period.
\end{abstract}

\section{INTRODUCTION}

The built environment is strongly influenced by thermal phenomena, such as anthropogenic heat, evaporation and evapotranspiration of plants, trees shading, ground cover like natural grass and artificial paving [1]. A cozy outdoor space provides a pleasant thermal comfort experience for people and effectively improves the quality of city life. However, people experience different thermal sensations when performing different activities outdoors [2]. Recently several indices have been developed to assess the human thermal comfort in outdoor spaces. Furthermore, these indices have been correlated to each other to select the most appropriate indices for applications in human thermal studies [3, 4]. Thermal comfort assessment is crucial to quantify the human thermal stress, (UTCI) universal thermal climate index, (PET) Physiological equivalent temperature and other thermal indices are designed for thermal and climate assessment $[5,6]$. Most of these indices integrate physical or microclimatic parameters (air temperature, relative humidity and wind velocity) and personnel human parameters (clothing and metabolic rate). The above indices are incorporated with urban and microclimatic design programs like Envi-met and RayMan to quantify the thermal comfort levels outdoors and to investigate the effect formal and vegetal composition on the urban thermal comfort [7]. The effect of natural elements on thermal outdoor comfort has been widely addressed, especially in hard climates. According to Lai et al. [8] and Morille and Musy [9] the vegetation improves the thermal conditions by means of two effects; shading by trees canopy and evapotranspiration effect. While water bodies can naturally improve the thermal comfort levels in outdoor spaces through evaporation effect $[10,11]$. Other studies with different thermal issues and differentiated solutions [12-21].

Today we are witnessing thermal-responsive strategies that involve natural design outdoors to enhance the thermal outdoor comfort levels. The purpose of this research is to see how natural factors such as vegetation and water bodies might improve the outdoor thermal comfort levels of Martyrs Square in Guelma, Algeria, throughout the summer. The scientific process involved recording microclimate measurements at several points throughout the area during the hottest months of 
2019, which were then used as input to construct four scenarios using the Envi-Met model to investigate the influence of natural components on outdoor thermal comfort. The PET index and microclimatic variation were measured over a 12-hour period and used to estimate different simulations' thermal outdoor comfort levels.

\section{METHODS}

This study aims to investigate the effect of vegetation and water bodies to enhance outdoor thermal comfort levels of Martyrs square located in Guelma city during summertime. The scientific methodology was done in two main steps. First, real microclimate data was obtained through filed measurements at multiple locations within the square. Second, microclimate data was used as input in Envi-Met model to simulate four scenarios of Martyrs square. Microclimate variation and PET index were obtained over a period of 12 hours and used to quantify the thermal outdoor comfort levels in different simulations. Figure 1 shows methodological framework of the investigation.

\subsection{Field Measurements}

Microclimate data was obtained through field measurements conducted in July 21st, 2019. We obtained an hourly record of air temperature, relative humidity, and wind speed, in three different locations (P1: Vegetal point; P2: Wet point; P3: Free point) within Martyrs square from 09:00 to 21:00. Testo 480 - AG 501 1ST, 05634800 is the instrument used in measurements, it is about a multifunction tool equipped with digital probes used as thermo-hygrometer and as anemometer, Figure 2.

\subsection{PET and outdoor thermal comfort levels}

PET- Equivalent Physiological Temperature is derived from the energy model (MEMI: Munich Energy-balance Model), it is a two-node model that models the thermal conditions of the human body in a physiologically relevant way [22]. PET is applicable, both for the study indoor and outdoor, its calculation involves dry temperature, relative humidity, wind speed and mean radiant T. Physiological stress grades of PET index are categorized into ten scales as shown in Table 1.

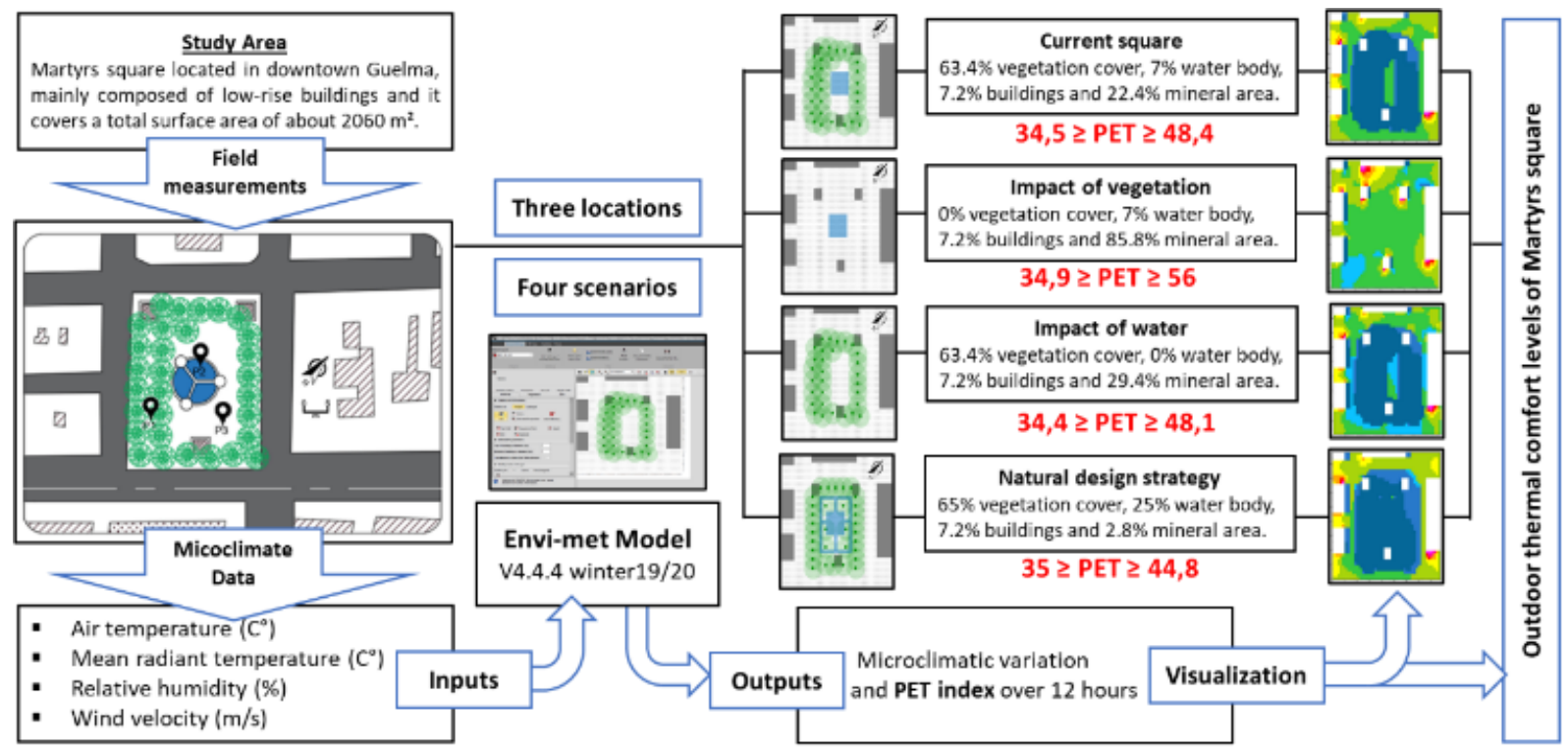

Figure 1. Diagram showing the methodology to quantify the outdoor thermal comfort levels

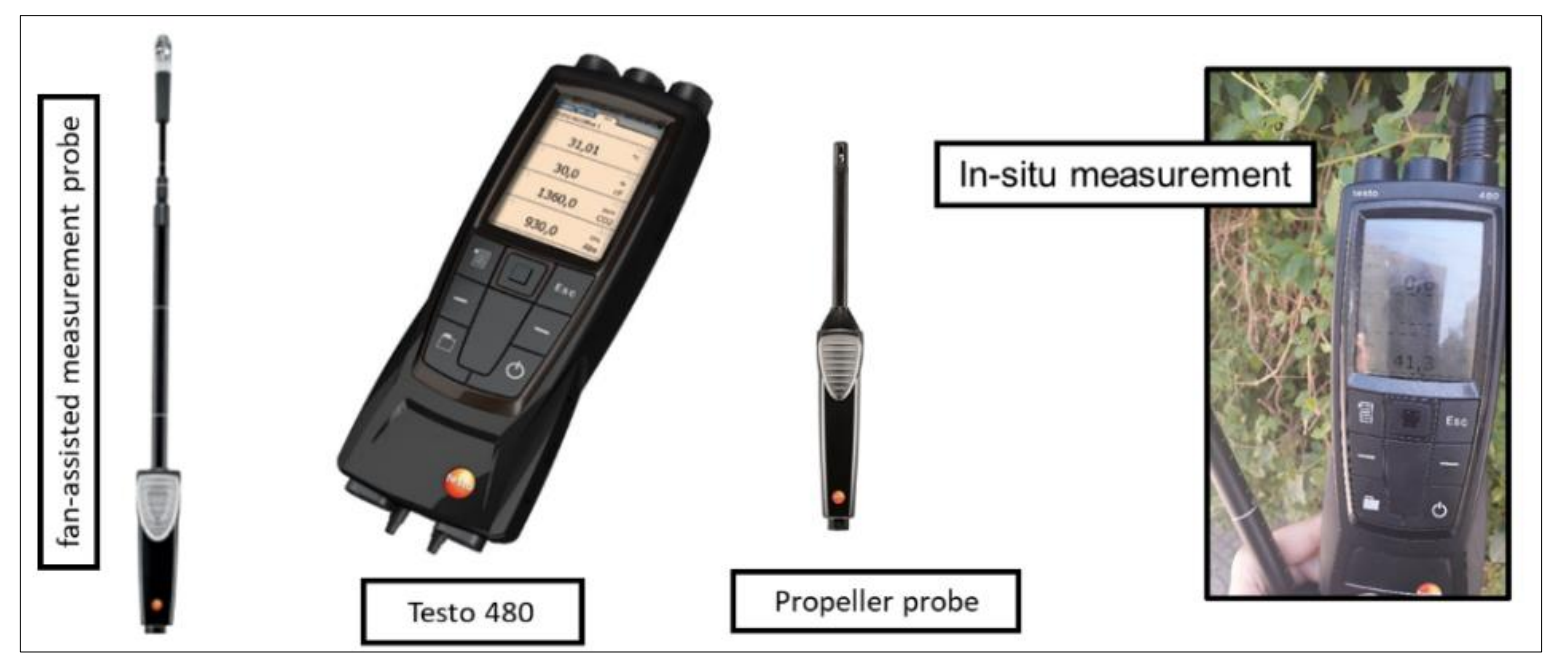

Figure 2. The instrument used in measurements Testo 480 - AG 501 1ST, 05634800 
Table 1. PET thermal stress categorization [4]

\begin{tabular}{|c|c|c|}
\hline PET & Thermal Perception & Grade of Physiological Stress \\
\hline$<4$ & Very cold & Extreme cold stress \\
\hline $4-8$ & Cold & Strong cold stress \\
\hline $8-13$ & Cool & Moderate cold stress \\
\hline $18-23$ & Comfortable & No thermal stress \\
\hline $23-29$ & Slightly warm & Slight heat stress \\
\hline $29-35$ & Warm & Moderate heat stress \\
\hline $35-41$ & Hot & Strong heat stress \\
\hline$>41$ & Very hot & Extreme heat stress \\
\hline
\end{tabular}

\section{NUMERICAL SIMULATION}

\subsection{Envi-met model}

The effect of vegetation and water on thermal comfort levels was investigated through atmospheric simulations of four scenarios of Martyrs square using real microclimate data obtained on July 21st, 2019.

ENVI-met program is a numerical tool used in bioclimatic outdoor design [7, 23]. It can calculate microclimatic parameters, such as air temperature, relative humidity, wind velocity and other parameters [24]. The atmospheric outputs of each scenario were used to calculate PET index through Biomet process, the whole outputs generated by Envi-met over 12 hours were visualized by LEONARDO module. Table 2 presents the simulation framework.

Table 2. Envi-met simulation framework of four scenarios of Martyrs square

\begin{tabular}{|c|c|}
\hline \multicolumn{2}{|c|}{ Simulation process parameters by Envi-met model } \\
\hline Location & Guelma city, Algeria \\
\hline Climate & Semi-arid \\
\hline Simulation date & July $22^{\text {nd }}, 2019$ \\
\hline Simulation time & From 09:00 am. to 09:00 pm \\
\hline $\begin{array}{c}\text { PET index } \\
\text { calculation }\end{array}$ & Biomet process \\
\hline $\begin{array}{c}\text { Meteorological } \\
\text { inputs }\end{array}$ & $\mathrm{Ta}\left({ }^{\circ} \mathrm{C}\right), \mathrm{RH}(\%)$ and $\mathrm{Wv}(\mathrm{m} / \mathrm{s})$ \\
\hline $\begin{array}{c}\text { Results } \\
\text { visualization }\end{array}$ & Leonardo visualization tool \\
\hline & $\begin{array}{c}\text { Natural stone walls } \\
\text { Red tile roof }\end{array}$ \\
Buildings & Albedo walls $=0.2$ \\
& Albedo roof $=0.08$ \\
\hline Vegetation & $\begin{array}{r}\text { Ficus trees: Evergreen, dense and with } \\
\text { round canopy. }\end{array}$ \\
& Albedo trees $=0.2$ \\
\hline
\end{tabular}

\section{RESULTS AND DISCUSSION}

\subsection{Envi-met model validation}

\subsubsection{Measurements and simulation}

The main objective of simulating the base case scenario of Martyr's square is to quantify the current thermal comfort levels under different environmental conditions using a set of microclimatic parameters and PET thermal index. To do so, we have first to validate the simulation model by comparing at least two microclimatic parameters at measuring points P1, P2 and P3 to the corresponding Envi-met simulation outputs. Figure 3(a) and 3(b) presents the comparison between measured and simulated relative humidity and air temperature, respectively. It can be seen that simulated and measured values of both microclimatic parameters have the same trend for the three measuring points with relatively higher curves for simulated values, corresponding to respective mean differences of $0.3^{\circ} \mathrm{C}$ in air temperature and $1 \%$ in relative humidity. This means that Envi-met model is able to reproduce reliable data and it is suitable to meet the objectives emphasized by this study, which agrees with the study conducted in the same physical context by Sayad and Alkama [25].

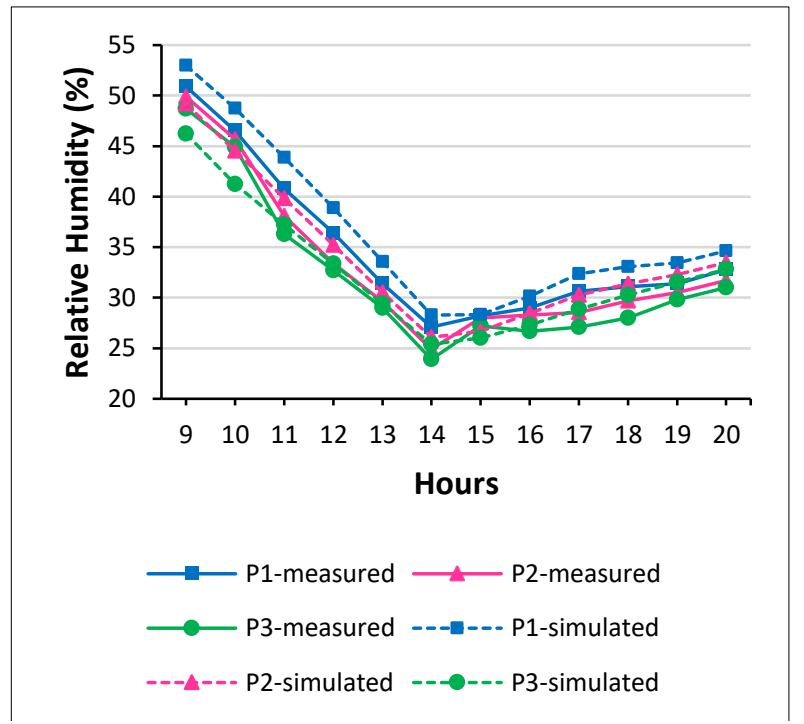

(a) Relative humidity

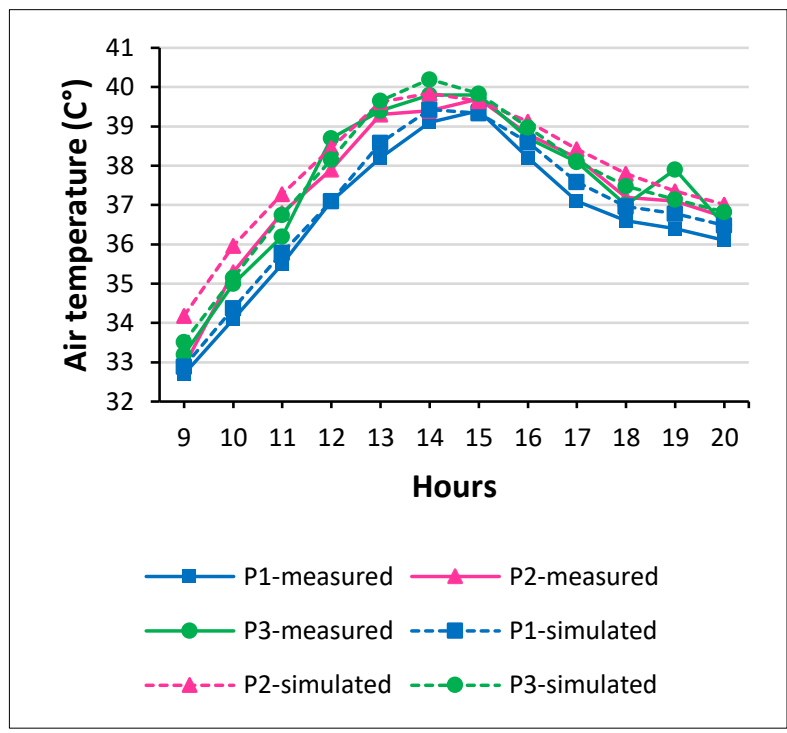

(b) Air temperature

Figure 3. Comparison between measured and simulated data measuring points $\mathrm{P} 1, \mathrm{P} 2$ and $\mathrm{P} 3$

\subsection{Thermal outdoor comfort levels}

\subsubsection{Quantification and enhancement}

As the main aim of our study is to investigate the effect of vegetation and water bodies to enhance thermal comfort levels of Martyrs square, simulation of different scenarios is crucial. Figures 4-8 show the results of comparing simulated parameters and PET index in all scenarios: the current square 
design, the square stripped of natural elements and a proposed natural design strategy.

\subsubsection{Current thermal comfort levels}

Clearly, natural elements play a key role to enhance the thermal comfort levels in outdoor spaces. The results of the base case scenario of Martyrs square indicate thermal comfort levels are ranging a way: $34.5 \geq \mathrm{PET} \geq 48.4$ corresponding to moderate to strong heat stress. It appears from the graphs in Figure 4 and 8 that PET and Tmrt have the same trend, which means that the thermal comfort levels are influenced by the mean radiant temperatures. However, the current natural design generates three hierarchical levels of thermal comfort; morning level with PET $\leq 45^{\circ}$; afternoon level where $45^{\circ} \geq$ PET $\geq 41^{\circ}$ and evening level PET $\leq 38^{\circ}$. Since the mean radiant temperature is the combination of different temperatures within the atmosphere, tree removal has significantly influenced the thermal conditions including the human skin temperatures who should lie at $36^{\circ}$. Hence, we obtained a respective increase of $17.7^{\circ} \mathrm{C}$ in Tmrt, $1.6^{\circ} \mathrm{C}$ in air temperature, $1.8^{\circ} \mathrm{C}$ in skin temperature and $7.1^{\circ} \mathrm{C}$ in PET index, corresponding to extreme heat stress. In parallel, the relative humidity has decreased by $4.1 \%$. The possible interpretation is that urban trees in Martyr's square have controlled the transmitted solar radiation through two effects shading effect by trees canopy and evapotranspiration effect by the leaf mass of trees. The thermal local effect of the water in daytime is considered as negligible compared to vegetation where PET was $34.4 \geq$ PET $\geq 48.1$, which is relatively equal to that of the current natural design. Therefore, removing the water body has generated more minerality, which increases the transmitted amount of shortwave solar radiation. The reduction in Tmrt during hot hours indicates that the surface area of water bodies is decisive in terms of absorption of solar radiation in outdoor spaces.

\subsubsection{Optimal thermal comfort levels}

Based on the previous results, we have proposed a natural design strategy to enhance the thermal comfort levels of Martyr's square (See Figure 1). The proposed strategy involves combining a new trees ratio and linear water bodies: $65 \%$ vegetation cover, $25 \%$ water body, $7.2 \%$ buildings and $2.8 \%$ mineral area.

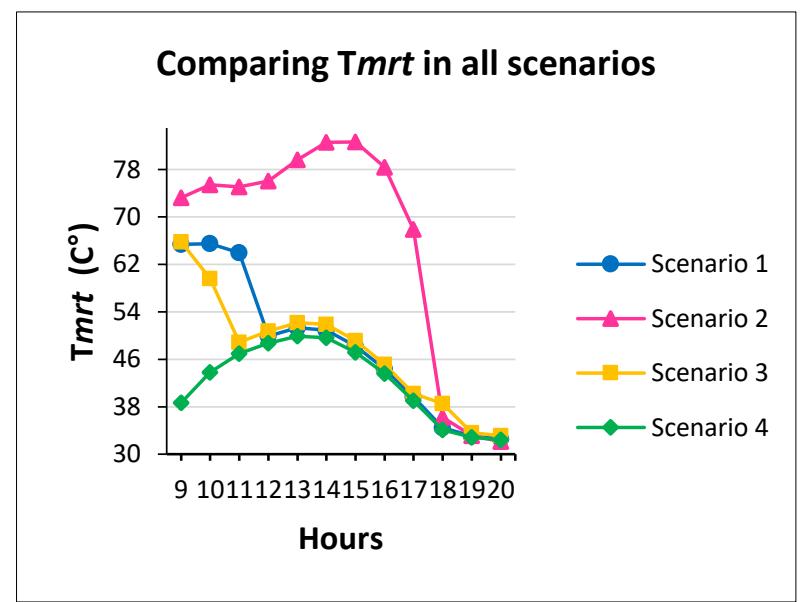

Figure 4. Comparison of Tmrt in all scenarios of Martyrs square. Leonardo, Envi-Met V4.4.4

Initially, the natural design strategy generates two thermal comfort levels; morning and evening period with PET $\leq$ $41^{\circ}$ correspending to moderate heat stress and afternoon level with $\mathrm{PET} \leq 48^{\circ}$ corresponding to strong heat stress. Furthermore, the overall results reveal that combining linear water bodies with dense trees can reduce the PET index to $9.5^{\circ} \mathrm{C}$ in the morning period. The enhancement mechanisms of microclimate parameters that underly these levels are as flow:

\section{- Mean Radiant Temperature}

Opting for dense trees aims to protect users from unwanted radiation by offering a large shaded area. In fact, the new vegetal ratio has contributed to reduce the Tmrt throughout the day with mean $\Delta \mathrm{Tmrt}=6^{\circ} \mathrm{C}$ and $\max \Delta \mathrm{Tmrt}=26.7^{\circ} \mathrm{C}$ at $09: 00$ am. This means that the leaf mass in the proposed natural strategy is able to block the received solar radiation (Figure 4).

\section{- $\quad$ Air and Skin Temperatures}

Blocking the received solar radiation within martyr's square involves a bi-regulatory process.

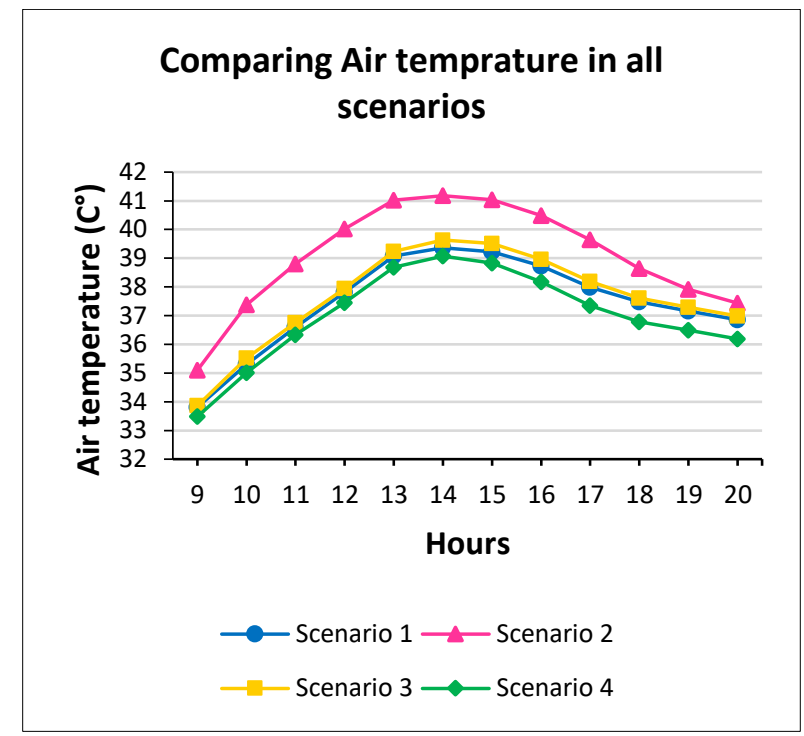

(a)

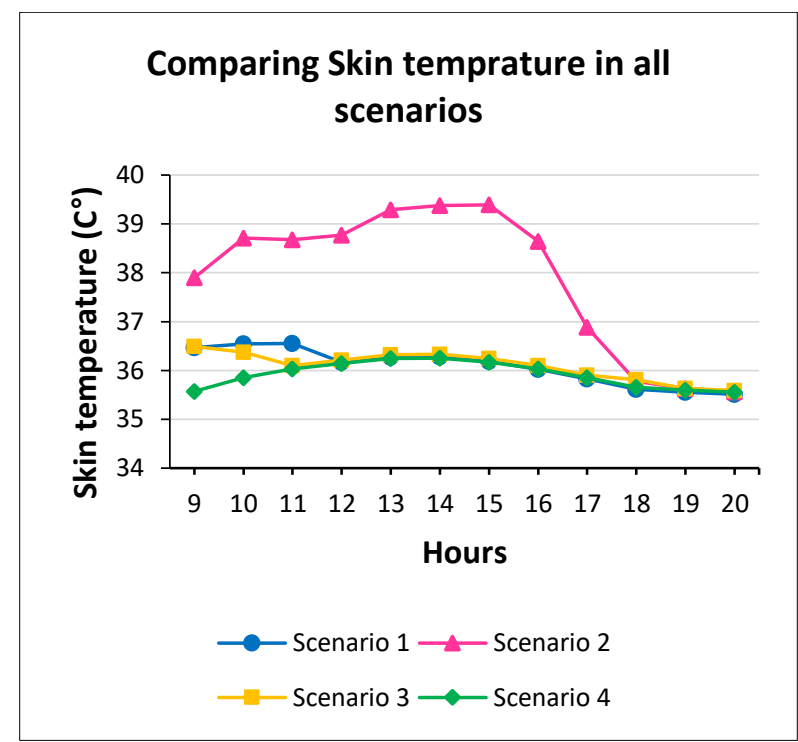

(b)

Figure 5. Comparison of (a) air and skin (b) temperature in all scenarios of Martyrs square. Leonardo, Envi-Met V4.4.4 
Once the shortwave radiation is blocked by the dense leaf mass of trees, the longwave radiation propagates below its rounded and wide canopy, whose shadow radius exceeds $4 \mathrm{~m}$. This mainly contributes to lowering the air temperature of Martyr's square in summertime and subsequently maintain the skin temperature within its norms of $35^{\circ} \mathrm{C}$ to $36^{\circ} \mathrm{C}$ (Figure 5 (a) and (b)).

\section{- Relative Humidity}

Among four simulated scenarios, the fourth one has the highest relative humidity, mainly caused by two effects, transpiration effect through trees leaves and water evaporation effect. Thereby, the quantity of water sprinkled by natural elements in Martyr's square has increased by $4.6 \%$ in comparison with the stripped case of vegetation (Figure 6).

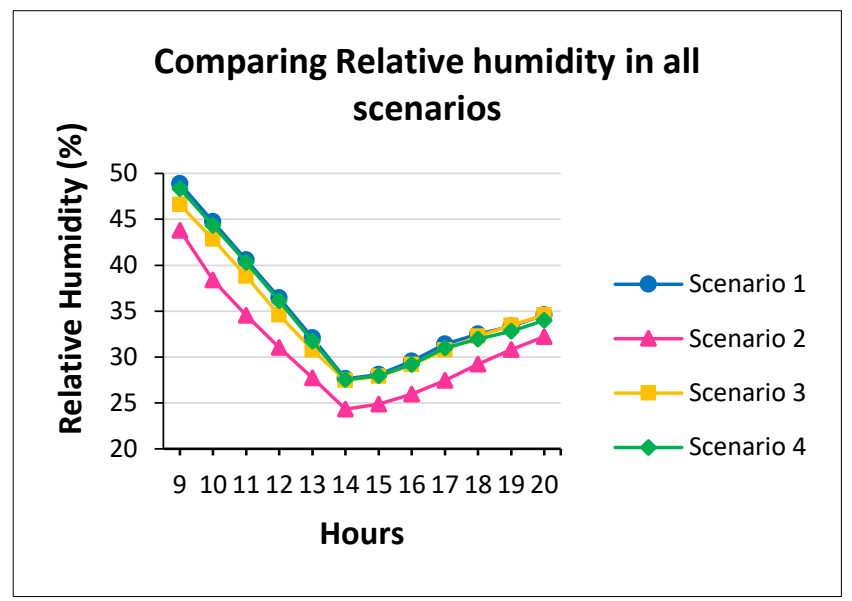

Figure 6. Comparison of relative humidity in all scenarios of Martyrs square. Leonardo, Envi-Met V4.4

\section{- Wind Speed}

By comparing the wind speed values in various scenarios, we can conclude that the air movement was obstructed by the imposing mass of trees. Thus, the proposed trees in the natural design strategy have the highest obstruction effect (Figure 7).

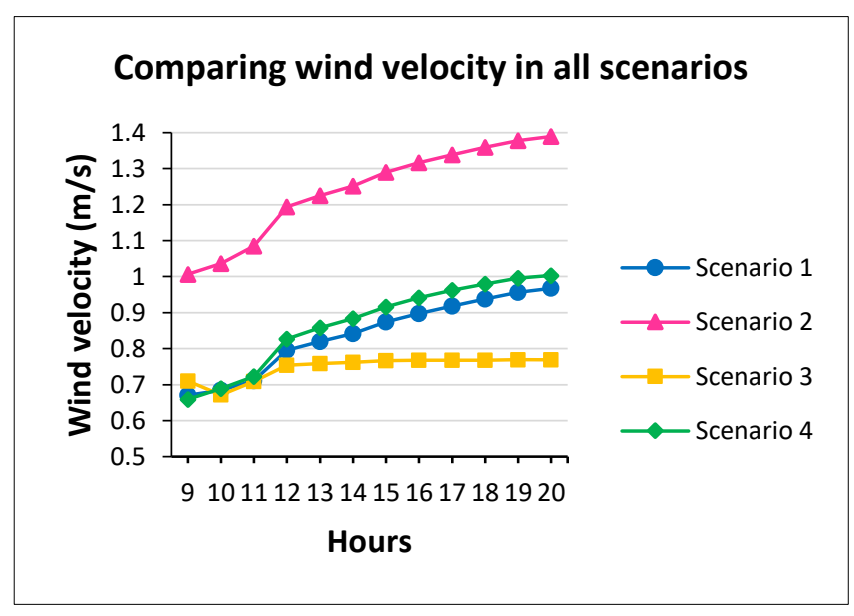

Figure 7. Comparison of wind velocity in all scenarios of Martyrs square. Leonardo, Envi-Met V4.4.4

\section{- PET thermal index}

Regardless of the effect of wind obstruction, a considerable reduction in air temperature and Tmrt with an increase of relative humidity in summertime could lead to positive microclimatic regulation as well as a significant enhancement of thermal comfort levels outdoors, which highly agrees with previous studies [26].

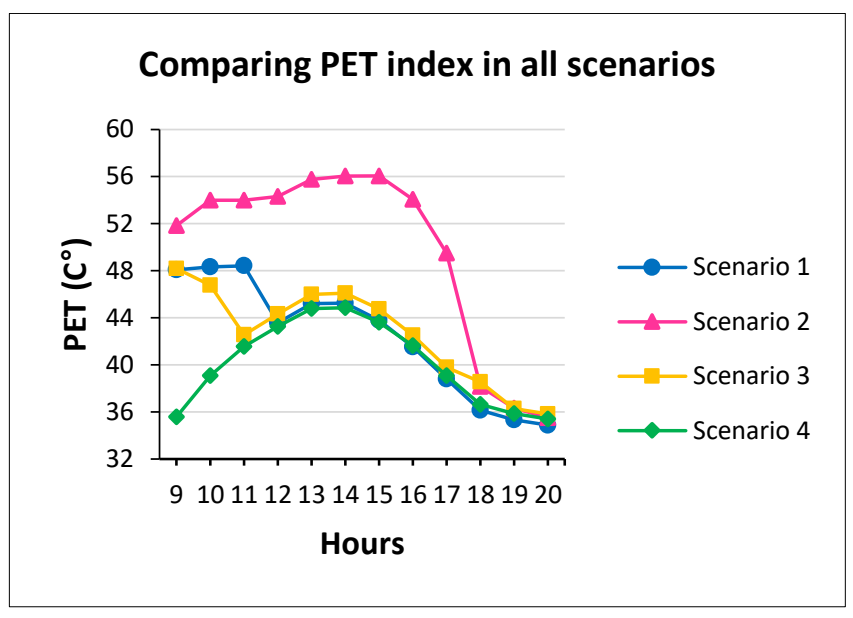

Figure 8. Comparison of PET thermal index in all scenarios of Martyrs square. Leonardo, Envi-Met V4.4.4

In sum, the natural design strategy has enhanced the thermal comfort levels through a set of parameters and determining qualities of natural elements, such as providing shade and cooling down the surrounding environment through the evaporation and evapotranspiration effects (Figure 8).

\section{CONCLUSION}

The effects of natural design strategy on thermal comfort levels in outdoor spaces in Guelma city with semi-arid climate has been investigated in this study. Real microclimate has been measured and used to validate Envi-Met model to simulate various scenarios. The effect of vegetation and water bodies on thermal comfort levels has been discussed in deferent natural design strategies based on microclimate variation and PET index. Findings indicate that the current natural design generates three hierarchical levels of thermal comfort; morning level where PET $\leq 45^{\circ}$; afternoon level where $45^{\circ} \geq$ $\mathrm{PET} \geq 41^{\circ}$ and evening level PET $\leq 38^{\circ}$. Removing natural elements has significantly influenced the thermal comfort levels, the thermal effect of the water body in daytime is considered as negligible compared to vegetation. The natural design strategy generates two thermal comfort levels; morning and evening level with PET $\leq 41^{\circ}$ and afternoon level with PET $\geq 48^{\circ}$. The results reveal that combining linear water bodies with dense trees can reduce the PET index to $9.5^{\circ} \mathrm{C}$ in the morning period.

\section{REFERENCES}

[1] Zhao, C., Fu, G., Liu, X., Fu, F. (2011). Urban planning indicators, morphology and climate indicators: A case study for a north-south transect of Beijing, China. Building and Environment, 46(5): 1174-1183. https://doi.org/10.1016/j.buildenv.2010.12.009

[2] Sayad, B., Alkama, D. (2020b). Adaptive human mechanisms of outdoor thermal comfort in cold stress. 
ICCAUA2020 Conference Proceedings, pp. 31-37. https://doi.org/10.38027/n32020iccaua316345

[3] Staiger, H., Laschewski, G., Matzarakis, A. (2019). Selection of appropriate thermal indices for applications in human biometeorological studies. Atmosphere, 10(1): 1-15. https://doi.org/10.3390/atmos10010018

[4] Zare, S., Hasheminejad, N., Shirvan, H.E., Hemmatjo, R., Sarebanzadeh, K., Ahmadi, S. (2018). Comparing universal thermal climate index (UTCI) with selected thermal indices/environmental parameters during 12 months of the year. Weather and Climate Extremes, 19: 49-57. https://doi.org/10.1016/j.wace.2018.01.004

[5] Blazejczyk, K., Epstein, Y., Jendritzky, G., Staiger, H., Tinz, B. (2012). Comparison of UTCI to selected thermal indices. International Journal of Biometeorology, 56(3): 515-535. https://doi.org/10.1007/s00484-011-0453-2

[6] Matzarakis, A., Muthers, S., Rutz, F. (2014). Application and comparison of UTCI and pet in temperate climate conditions. Finisterra, 49(98): 21-31. https://doi.org/10.18055/Finis6453

[7] Sayad, B., Alkama, D. (2019). Study of the microclimate behavior in spaces between buildings: Which strategy to adopt during cold season in Guelma's public SPACES? AIP Conference Proceedings, 2123(1). https://doi.org/10.1063/1.5117038

[8] Lai, D., Liu, W., Gan, T., Liu, K., Chen, Q. (2019). A review of mitigating strategies to improve the thermal environment and thermal comfort in urban outdoor spaces. Science of the Total Environment, 661: 337-353. https://doi.org/10.1016/j.scitotenv.2019.01.062

[9] Morille, B., Musy, M. (2017). Comparison of the Impact of three climate adaptation strategies on summer thermal comfort - cases study in Lyon, France. Procedia Environmental Sciences, 38: 619-626. https://doi.org/10.1016/j.proenv.2017.03.141

[10] Jacobs, C., Klok, L., Bruse, M., Cortesão, J., Lenzholzer, S., Kluck, J. (2020). Are urban water bodies really cooling? Urban Climate, 32: 100607. https://doi.org/10.1016/j.uclim.2020.100607

[11] Sayad, B., Alkama, D. (2021). A combined approach to predict the human thermal comfort in downtown Guelma-Algeria. International Journal of Innovative Studies in Sociology and Humanities, 6(1): 1-14. https://doi.org/10.20431/2456- 4931.060101

[12] Alawee, W.H., Al-Sumaily, G.F., Dhahad, H.A., Thompson, M.C. (2021). Numerical analysis of nonDarcian mixed convection flows in a ventilated enclosure filled with a fluid-saturated porous medium. Thermal Science and Engineering Progress, 100922. https://doi.org/10.1016/j.tsep.2021.100922

[13] Xiong, P.Y., Almarashi, A., Dhahad, H.A., et al. (2021). Nanomaterial transportation and exergy loss modeling incorporating CVFEM. Journal of Molecular Liquids, 330: 115591 https://doi.org/10.1016/j.molliq.2021.115591

[14] Essa, F.A., Alawee, W.H., Mohammed, S.A., Abdullah, A.S., Omara, Z.M. (2021). Enhancement of pyramid solar distiller performance using reflectors, cooling cycle, and dangled cords of wicks. Desalination, 506: 115019. https://doi.org/10.1016/j.desal.2021.115019
[15] Yao, S.W., Alawee, W.H., Dhahad, H.A., Issakhov, A., Bui, X.V. (2021). Convective transportation of ferrofluid through a chamber. Applied Nanoscience, 1-13. https://doi.org/10.1007/s13204-021-01728-4

[16] Rihan, A.A., Mohamed, T.A., Alawee, W.H. (2021). Physical simulation for the flow in straight and rectangular loop manifolds. Journal of Engineering, 27(3): 15-32. https://doi.org/10.31026/j.eng.2021.03.02

[17] Li, J., Alawee, W.H., Rawa, M.J., Dhahad, H.A., Chu, Y.M., Issakhov, A., Abu-Hamdeh, N.H., Hajizadeh, M.R. (2021). Heat recovery application of nanomaterial with existence of turbulator. Journal of Molecular Liquids, 326:

115268 .

https://doi.org/10.1016/j.molliq.2020.115268

[18] Ghadhban, S.A., Alawee, W.H., Dhahad, H.A. (2021). Study effects of bio-inspired flow filed design on Polymer Electrolyte Membrane fuel cell performance. Case Studies in Thermal Engineering, 24: 100841. https://doi.org/10.1016/j.csite.2021.100841

[19] Alawee, W.H., Mohammed, S.A., Dhahad, H.A., Abdullah, A.S., Omara, Z.M., Essa, F.A. (2021). Improving the performance of pyramid solar still using rotating four cylinders and three electric heaters. Process Safety and Environmental Protection, 148: 950-958. https://doi.org/10.1016/j.psep.2021.02.022

[20] Xiong, P.Y., Almarashi, A., Dhahad, H.A., Alawee, W.H., Issakhov, A., Chu, Y.M. (2021). Nanoparticles for phase change process of water utilizing FEM. Journal of Molecular $\quad$ Liquids, 334: 116096. https://doi.org/10.1016/j.molliq.2021.116096

[21] Ge-JiLe, H., Alawee, W.H., Dara, R.N., Issakhov, A., Selim, M.M., Hajizadeh, M.R. (2021). Influence of Lorentz and permeability on migration of nanoparticle. International Journal of Modern Physics C. https://doi.org/10.1142/S0129183121501047

[22] Hoppe, P. (1999). The physiological equivalent temperature - a universal index for the biometeorological assessment of the thermal environment. International Journal of Biometeorology, 43(2): 71-75.

[23] Tsitoura, M., Michailidou, M., Tsoutsos, T. (2017). A bioclimatic outdoor design tool in urban open space design. Energy and Buildings, 153: 368-381. https://doi.org/10.1016/j.enbuild.2017.07.079

[24] Elwy, I., Ibrahim, Y., Fahmy, M., Mahdy, M. (2018). Outdoor microclimatic validation for hybrid simulation workflow in hot arid climates against ENVI-met and field measurements. Energy Procedia, 153: 29-34. https://doi.org/10.1016/j.egypro.2018.10.009

[25] Sayad, B., Alkama, D. (2021b). Microclimatic regulation of palm trees in semi-arid environment during heat stress. Journal of Fundamental and Applied Sciences, 13(2): 694-707. https://doi.org/10.4314/jfas.v13i2.4

[26] Sayad, B., Alkama, D. (2020a). Potential contribution of green and blue technologies to reduce heat stress in outdoor spaces, case of Guelma city-Algeria. A+Arch Design International Journal of Architecture and Design, 6(1): 23-32. https://doi.org/10.17932/IAU.ARCH.2015.017/arch_v0 $6 \mathrm{i} 1002$ 